\title{
Drug resistance in a non-hemolytic Streptococcus sp. isolated from cultured yellowtail Seriola quinqueradiata
}

\author{
T. Aoki, K. Takami, T. Kitao \\ Department of Fisheries, Faculty of Agriculture, Miyazaki University, Miyazaki 889-21, Japan
}

\begin{abstract}
The antibacterial activities of 19 chemotherapeutic agents were tested against 370 strains of a non-hemolytic Streptococcus sp. pathogenic for a marine fish, the yellowtail Seriola quinqueradiata. The strains were isolated from cultured yellowtail in 1986 and 1987. Sixty-two of the tested strains showed resistance to macrolide antibiotics (MLs), lincomycin (LIM), tetracycline (TC), and chloramphenicol (CP). These resistant strains were classified into intermediate- and high-level resistance to MLs, LIM, TC, or CP. Intermediate-level resistance was constitutive and the responsible resistance determinants were not transferred to $S$. faecalis JH2-2 or to Streptococcus sp. SSS-1, the latter a yellowtail isolate. On the other hand, high-level resistance to MLs, LIM, and TC and to MLs, LIM, and $\mathrm{CP}$ was inducible and transferable to $\mathrm{S}$. faecalis JH2-2 and to Streptococcus sp. SSS-1. These drugresistant strains of the non-hemolytic Streptococcus sp., capable of transferring their resistance, were first isolated in cultured yellowtail in various areas of Japan.
\end{abstract}

\section{INTRODUCTION}

Epizootics due to a Streptococcus sp. in cultured yellowtail Seriola quinqueradiata have been observed frequently in various world locations since 1974 and have caused serious economic damage to fish culture operations in Japan. The biochemical characteristics of the non-hemolytic Streptococcus sp. causing the infection closely resembled those of Streptococcus faecalis and S. faecium (Kusuda et al. 1976). However, this single species of Streptococcus did not belong to any of the described Lancefield groups (Kitao 1982).

For the treatment of streptococcal infections, the chemotherapeutics commonly used are macrolide antibiotics (MLs, e.g. erythromycin, spiramycin, kitasamycin, and josamycin) and lincomycin. MLs and lincomycin have shown strong antibacterial activity against Streptococcus sp. isolated from cultured yellowtail (Aoki et al. 1983). Recently, these antibiotics have on occasion been ineffective in treating the streptococcal infections. This phenomenon suggested the appearance of MLs and lincomycin-resistant Streptococcus sp. strains in yellowtail farms.

The resistance mechanism of Gram-positive cocci to MLs in human pathogens is well known (Saito et al. 1969, Lai \& Weisblum 1971, Lai et al. 1973, Skinner et al. 1983, Weisblum et al. 1971). The ML resistance of streptococci has been divided into 2 types: inducible and constitutive (Hyder \& Streitfeld 1973). ML resistance in Lancefield Group A, B, and D streptococci is transferable from the ML-resistant strains to sensitive ones via conjugation (Clewell 1981).

In the present study, strains of non-hemolytic Streptococcus sp. collected from marine fish farms were tested for their sensitivity to various chemotherapeutics, in particular MLs and lincomycin, to determine whether drug resistance explains the growing incidence of treatment failures on yellowtail farms. The drug-resistant strains detected were further studied for the transfer properties of their drug resistance.

\section{MATERIALS AND METHODS}

Bacterial strains. Three hundred and seventy strains of a non-hemolytic Streptococcus sp., collected in 1986 and 1987 from diseased, cultured yellowtail in various districts of Japan (Fig. 1), were used in the drug susceptibility tests.

Drug-resistant strains of Streptococcus sp. (Strains EH8632, EH8702, KG8703, ME8631, and ME8714) were selected at random and used for $\mathrm{ML}$, tetracycline 


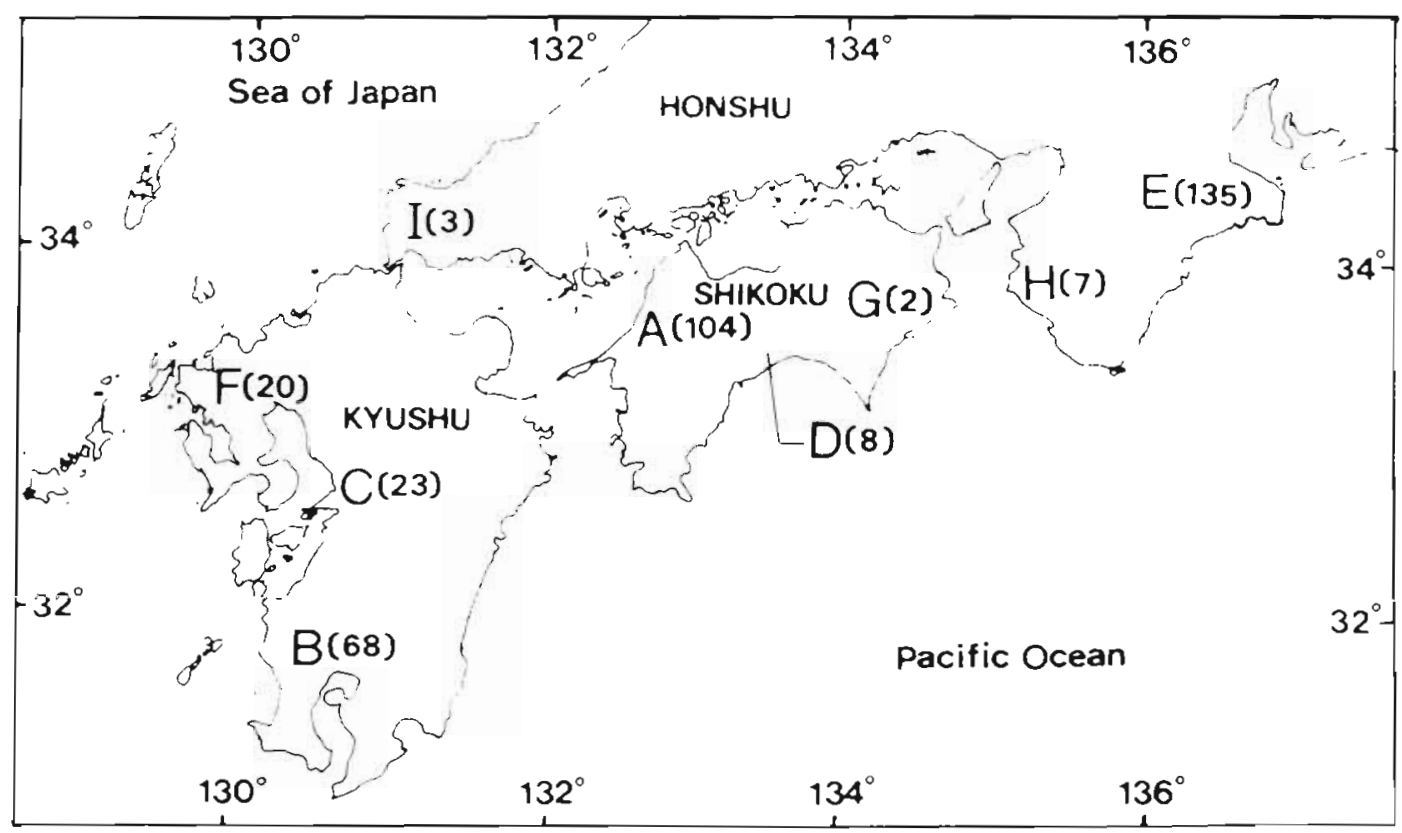

Fig. 1. Map of sampling areas. Letters represent the sampling locations: (A) Ehime; (B) Kagoshima; (C) Kumamoto; (D) Kochi; (E) Mie; (F) Nagasaki; (G) Tokushima; (H) Wakayama; and (I) Yamaguchi. Numbers in parentheses indicate number of isolated Streptococcus sp. strains at each location

(TC), and chloramphenicol (CP) induction tests and also as donors to permit estimates of the frequency of transfer of their drug-resistance determinants. $S$. faecalis JH2-2 (Jacob \& Hobbs 1974) and Streptococcus sp. SSS-1 (a derivative of Streptococcus sp. EH8727, highly resistant to streptomycin) were used as recipients for the transfer of drug-resistance determinants. The antibiotic resistance characteristics of the strains used are shown in Table 1.

Media. Heart infusion broth (Nissui) containing $0.2 \%$ glucose (HIG broth) and HIG containing $1.5 \%$ agar (HMG agar) (Nissui) were employed for the cultivation of the Streptococcus sp, and for selecting transconjugant cells

A sensitivity-disk medium (modified Mueller Hinton agar) (Nissui), supplemented with $0.2 \%$ glucose, was used for testing susceptibility to trimethoprim (TMP) and ormethoprim (OMP). HIG agar was used for tests with the remaining antibiotics and furazolidone (NF).

Drug sensitivity test. Minimal inhibitory concentrations (MICs) against Streptococcus sp. were determined by the serial 2 -fold dilution method in agar standardized by the Japan Society of Chemotherapy (Japan Society of Chemotherapy 1981). The MIC value was determined after incubation for $20 \mathrm{~h}$ at $25^{\circ} \mathrm{C}$.

The drugs used for the sensitivity tests were erythromycin (EM), oleandomycin (OM), triacethyloleandomycin (TAO), josamycin (JM), kitasamycin (KTM), midecamycin (MDM), spiramycin (SPM), lincomycin (LIM), ampicillin (ABP), cephalexin (CEX), cefazolin (CEZ), chloramphenicol (CP), tetracycline (TC), doxycycline (DOTC), streptomycin (SM), kanamycin (KM), NF, TMP, and OMP.

Induction of drug resistance. Five strains of Strep-

Table 1 Streptococcus sp. Properties of strains used in this study. See text for abbreviations

\begin{tabular}{|lll|}
\hline Strain & Resistance phenotype & Source \\
\hline Donor strains & & \\
Streptococcus sp. ME8631 & EM, OM, SPM., LIM, TC & Yellowtail \\
Streptococcus sp. ME8714 & EM, OM, SPM. LIM, TC & Yellowtail \\
Streptococcus sp. EH8632 & MLs, LIM, TC & Yellowtail \\
Streptococcus sp. EH8702 & MI.s, LIM, TC & Yellowtail \\
Streptococcus,sp. KG8703 & MLs, LIM, CP & Yellowtail \\
Recipient strains & & Jacob \& Hobbs $(1974)$ \\
S. faecalis JH2-2 & Fusidic acid, rifampicin & Derivative of EH8727 \\
Streptococcus sp. SSS-1 & SM & \\
\hline
\end{tabular}


tococcus sp. resistant to MLs, LIM, TC, or CP (Table 1) were cultured separately in HIG broth overnight. One $\mathrm{ml}$ of each culture was inoculated into $100 \mathrm{ml}$ of the same medium. After $30 \mathrm{~min}$ incubation, $6 \mathrm{ml}$ of each culture were added to $2 \mathrm{ml}$ of fresh HIG broth with or without various concentrations of drugs. The concentration incorporated into HIG were as follows: 0.05 or $0.1 \mu \mathrm{g} \mathrm{ml}^{-1}$ of EM and LIM, and 0.5 or $1.0 \mu \mathrm{g} \mathrm{ml} \mathrm{m}^{-1}$ of OM, SPM, TC, and CP for the induction of resistance. After $1 \mathrm{~h}$ induction with one drug at a time, drug resistance of induced cells was examined in HIG broth containing various concentrations of the appropriate drugs. Mixtures were aerobically incubated at $25^{\circ} \mathrm{C}$ and the turbidity measured at $30 \mathrm{~min}$ intervals at a wave length of $610 \mathrm{~nm}\left(\mathrm{OD}_{610}\right)$ until control cells (drugfree culture) reached an $\mathrm{OD}_{610}$ of 0.5 .

Antibiotic-resistant mutants. SM-resistant mutants were isolated by the method of Horodniceanu et al. (1979). Streptococcus sp. EH8727, which was isolated from yellowtail, was grown in $100 \mathrm{ml}$ of $\mathrm{HIG}$ broth overnight. Cells were harvested by centrifugation and resuspended in $1 \mathrm{ml}$ of $\mathrm{HIG}$ broth. The culture was then plated on HIG agar containing $8000 \mu \mathrm{g} \mathrm{m} \mathrm{m}^{-1} \mathrm{SM}$. Mutant colonies arose at a frequency of approximately $1 \times 10^{-10}$ per viable cell and the SM-resistant strain was designated as SSS-1.

Mating procedures. Mating in a liquid medium was performed as described by Dunny \& Clewell (1975). Cells of 5 antibiotic-resistant donor strains of Streptococcus sp. and cells of the recipient $S$. faecalis $\mathrm{JH} 2-2$ and Streptococcus sp. SSS-1 strains were cultured separately overnight in HIG broth. Donor and recipient cultures were mixed together at a ratio of 1 donor to 10 recipient cells $(0.5 \mathrm{ml})$ in a test tube. Mixtures with $\mathrm{JH} 2-2$ were incubated at $37^{\circ} \mathrm{C}$, and those with strain SSS- 1 at $30^{\circ} \mathrm{C}$, for $4 \mathrm{~h}$. Cultures were spread on HIG agar containing antibiotics appropriate for the selection of resistant recipients.

Mating on a membrane filter was done according to Burdett (1980), and $0.5 \mathrm{ml}$ of the donor strain cells was mixed with $4.5 \mathrm{ml}$ of cells of a recipient strain in a test tube. One ml of this mixture was collected on a millipore membrane filter (HAWP, $0.45 \mu \mathrm{m}$ pore size) and the filter was then placed on $\mathrm{HIG}$ agar at 37 or $30^{\circ} \mathrm{C}$ for $18 \mathrm{~h}$. After incubation, the cells on the filter were suspended in $5 \mathrm{ml}$ of HIG broth. The suspension was then plated on HIG agar containing antibiotics appropriate for the selection of trans-conjugants.

Antibiotics present in selective media were added at the following levels: $E M=0.4 \mu \mathrm{g} \mathrm{ml}^{-1}$ (donor was ME8631 or ME8714) or $25 \mu \mathrm{g} \mathrm{m} \mathrm{m}^{-1}$; $\mathrm{TC}=4 \mu \mathrm{g} \mathrm{ml}^{-1}$ (donor was ME8631 or ME8714) or $10 \mu \mathrm{g} \mathrm{ml}^{-1}$; CP $=10$ $\mu \mathrm{g} \mathrm{ml}^{-1}$; fusidic acid (Fus) $=25 \mu \mathrm{g} \mathrm{ml}^{-1}$; rifampicin (Rif) $=50 \mu \mathrm{g} \mathrm{ml}^{-1}$; and $\mathrm{SM}=1000 \mu \mathrm{g} \mathrm{ml}^{-1}$

The frequencies of transfer were expressed in terms of the number of trans-conjugants per number of donor strain cells.

\section{RESULTS}

\section{Minimal inhibitory concentrations}

The distribution of MICs of 19 chemotherapeutic agents against 370 strains of non-hemolytic Streptococcus sp. is shown in Fig. 2. The strains could be placed into 3 apparently discrete groups according to their MIC values to EM. These groups were termed sensitive, intermediate-level, and high-level resistant with MIC values ranging from 0.05 to $0.8,1.6$ to 3.1 , and $>100 \mu \mathrm{g} \mathrm{ml}^{-1}$, respectively. Of the 370 strains tested, 308 were sensitive to EM, 40 were intermediate-level, and the remaining 22 strains were high-level resistant to the drug. The strains were also separable into 3 groups of 308 sensitive, 40 intermediate-level, and 22 high-level resistant with regard to the pattern of the MICs of OM. In the case of TAO, JM, KTM, and MDM. the strains fell into 2 groups: 348 strains were sensitive to these chemically related drugs, and the remaining 22 strains were high-level resistant. No strains with intermediate-level resistance to these drugs were found. With SPM and LIM, the strains formed 3 groups: 308 strains were sensitive, 40 strains intermediate, and the remaining 22 were high-level resistant. The MIC values of LIM, EM, and TAO were less than $0.8 \mathrm{\mu g} \mathrm{ml}^{-1}$ for $90 \%$ of strains tested (Table 2). The 40 strains showing intermediate-level resistance to EM, OM, SPM, and LIM were the same, and the 22 strains with high-level resistance to MLs and LIM were also the same.

The MIC values of ABP ranged from 0.2 to $1.6 \mathrm{\mu g}$ $\mathrm{ml}^{-1}$, and no ABP-resistant strains were detected. CEX was ineffective against the tested strains but CEZ was moderately effective. All strains isolated in 1986 showed sensitivity to CP, and 9 of 219 strains in 1987 were resistant to $\mathrm{CP}$. Thirteen strains had a high resistance to TC, and 40 strains were moderately resistant their MIC values ranged from 3.1 to $6.2 \mu \mathrm{g} \mathrm{ml}^{-1}$. The MIC values of DOTC were slightly lower than those of the related compound TC. The MIC values of the aminoglycosides SM and KM ranged from 12.5 to 100 $\mu \mathrm{g} \mathrm{m} \mathrm{m}^{-1}$. NF, TMP, and OMP showed little activity against Streptococcus sp. (Table 2).

\section{Induction of drug resistance}

As shown in Table 3, the resistance levels of ME8631 and ME8714 encoded with intermediate-level resistance to EM, OM, SPM, and LIM were not induced after exposure to EM, OM, SPM, or LIM. High-level resist- 

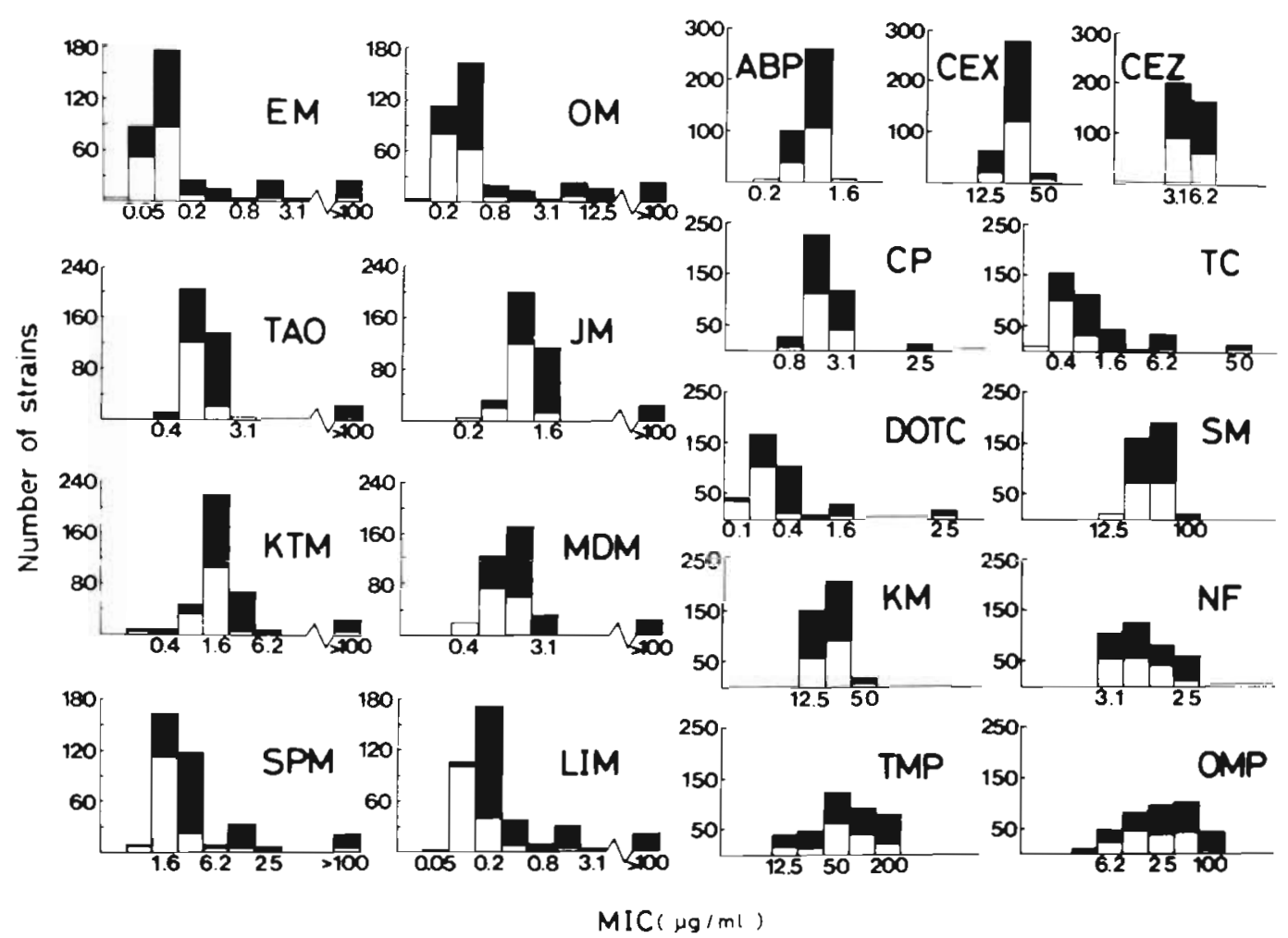

Fig. 2. Streptococcus sp. Minimal inhibitory concentrations (MICs) of various chemotherapeutics against naturally occurring nonhemolytic strains. Streptococcus sp. strains isolated in 1986 (ㄷ) and 1987 ( $)$. Abbreviations are: (EM) erythromycin; (OM) oleandomycin; (TAO) triacetyloleandomycin; (JM) josamycin; (KTM) kitasamycin; (MDM) midecamycin; (SPM) spiramycin; (LIM) lincomycin; (ABP) ampicillin; (CEX) cephalexin; (CEZ) cefazolin; (CP) chloramphenicol; (TC) tetracycline; (DOTC) doxycycline; (SM) streptomycin; (KM) kanamycin; (NF) furazolidone; (TMP) trimethoprim; (OMP) ormethoprim

Table 2. Streptococcus sp. Minimal inhibitory concentrations (MICs) of chemotherapeutics for strains used in this study. See Fig. 2 for abbreviations. MIC for inhibition of 50 and $90 \%$ of the isolates (22 high-level resistant strains not included)

\begin{tabular}{|lccc|}
\hline \multirow{2}{*}{ Drug } & Range & \multicolumn{2}{c|}{$\left.\mathrm{MIC}(\mu \mathrm{g} \mathrm{m}]^{-1}\right)$} \\
& & $50 \%$ & $90 \%$ \\
\hline EM & $0.025-3.1$ & 0.32 & 0.36 \\
OM & $0.1-12.5$ & 1.47 & 1.64 \\
TAO & $0.4-3.1$ & 0.67 & 0.74 \\
JM & $0.2-1.6$ & 1.01 & 1.12 \\
KTM & $0.2-6.2$ & 1.85 & 2.05 \\
MDM & $0.4-3.1$ & 1.38 & 1.53 \\
SPM & $0.8-25$ & 4.15 & 4.61 \\
LM & $0.05-3.1$ & 0.30 & 0.33 \\
ABP & $0.2-1.6$ & 0.70 & 0.78 \\
CEX & $12.5-50$ & 24.29 & 26.99 \\
CEZ & $3.1-6.2$ & 4.51 & 5.01 \\
CP & $0.8-3.1$ & 2.02 & 2.24 \\
TC & $0.2-6.2$ & 1.27 & 1.41 \\
DOTC & $0.1-1.6$ & 0.36 & 0.40 \\
SM & $12.5-100$ & 39.63 & 44.03 \\
KM & $12.5-50$ & 20.88 & 23.20 \\
NF & $3.1-25$ & 9.60 & 10.67 \\
TMP & $12.5-200$ & 86.86 & 96.51 \\
OM.P & $3.1-100$ & 34.25 & 38.06 \\
\hline
\end{tabular}

Table 3. Streptococcus sp. Type of induction of macrolide and lincomycin resistance. See Fig. 2 for abbreviations. (I: inducible, C: constitutive)

\begin{tabular}{|lcccc|}
\hline \multirow{2}{*}{ Strain } & \multicolumn{4}{c|}{ Inducer } \\
& EM & OM & SPM & LIM \\
\hline EH8632 & I & I & I & I \\
EH8702 & I & I & I & I \\
KG8703 & I & I & I & I \\
ME8631 & C & C & C & C \\
ME8714 & C & C & C & C \\
& & & & \\
\hline
\end{tabular}

ance in EH8632, EH8702, and KG8703 to MLs and LIM was induced after exposure to EM, OM, SPM, or LIM.

The TC resistance levels of ME8631 and ME8714 were not increased after induction with $0.5 \mu \mathrm{g} \mathrm{ml}^{-1}$ of $\mathrm{TC}$. On the other hand, the resistance levels of EH8632 and EH8702 were increased by exposure to concentrations of TC equal to between 0.5 and 1.0 of the TC MIC value. Fig. 3 shows the results for Strains ME8714 and EM8702. The CP resistance of Strain KG8703 was increased to its resistance level by exposure to $1.0 \mathrm{\mu g}$ $\mathrm{ml}^{-1} \mathrm{CP}$ (data not shown). 

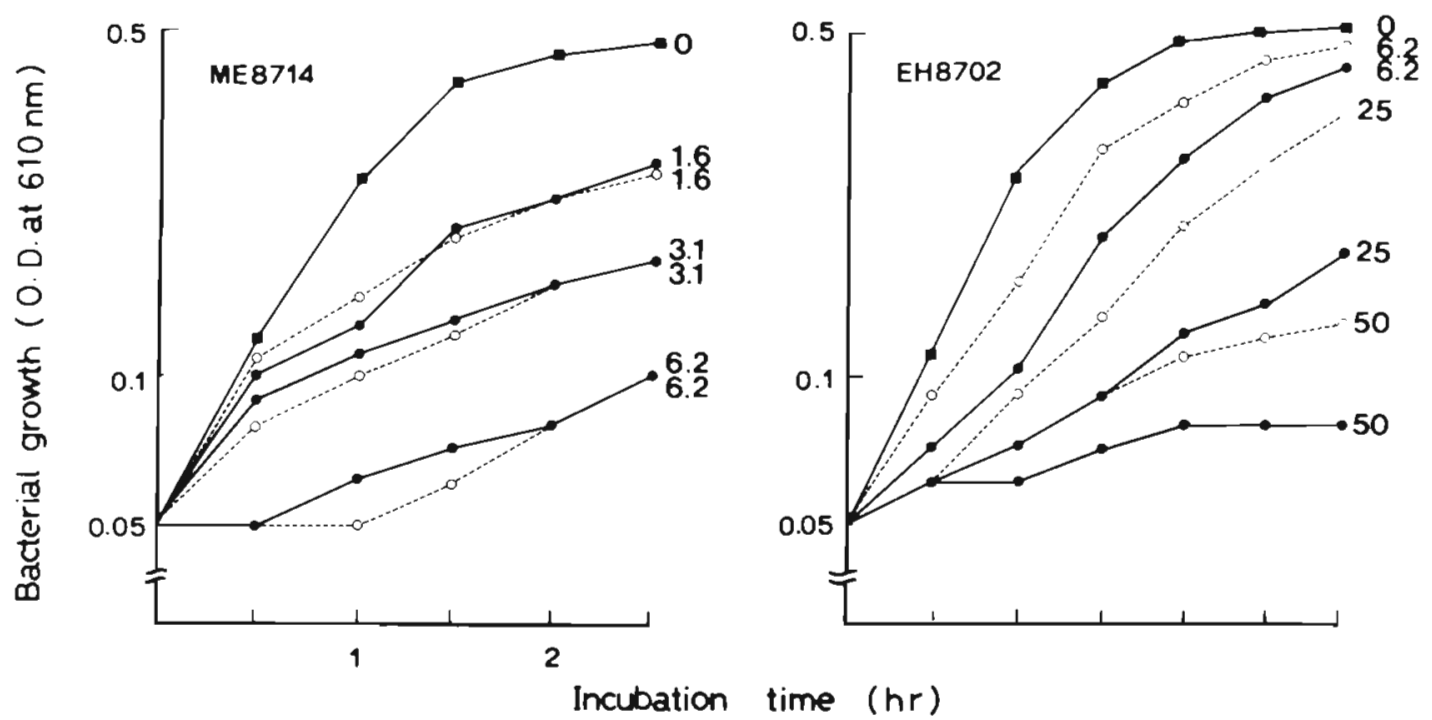

Fig. 3. Streptococcus sp. Induction of tetracycline resistance in Strain ME8714, but not in Strain EM8702. Cells were grown in HIG broth at $25^{\circ} \mathrm{C}$ with (---) or without (_- inducing antibiotics $\left(0.5\right.$ or $1.0 \mu \mathrm{g}$ tetracycline $\left.\mathrm{ml}^{-1}\right)$ for $1 \mathrm{~h}$ and were then challenged with various concentrations of tetracycline $\left(0,1.6,3.1,6.2,25\right.$, and $\left.50 \mu \mathrm{g} \mathrm{ml}^{-1}\right)$

\section{Transferability by conjugation}

Determinants of middle-level resistance to MLs, LIM, and TC were not transferred from ME8631 and ME8714 to recipient strains of Streptococcus faecalis JH2-2 and Streptococcus sp. SSS-1 (Table 4). On the other hand, 13 strains exhibiting high resistance to MLs, LIM, and TC transferred their drug resistance to JH2-2 and SSS-1 by mixed cultivation. Transferable drug resistance was found in 9 strains that showed high resistance to MLs, LIM, and CP. It was found that all the drug resistance markers of MLs, LIM, TC, and MLs, LIM, CP were transferable together.

The transfer frequencies of drug-resistant determinants from Streptococcus sp. EH8632, EH8702, and KG8703 strains to the recipients JH2-2 and SSS-1 ranged from $10^{-6}$ to $10^{-9}$ using the liquid medium mating method, and from $10^{-3}$ to $10^{-5}$ using the membrane filter method. The frequencies of transfer of drug resistance determinants to Streptococcus sp. SSS-1 were higher than those to $S$. faecalis $\mathrm{JH} 2-2$

\section{DISCUSSION}

This is the first report documenting the occurrence of drug resistance in strains of pathogenic Streptococcus sp. isolated from cultured yellowtail Seriola quinqueradiata. The drug-resistant Gram-positive strains described here appeared first in marine fish farms and their appearance is likely attributable to the extensive use of chemotherapeutics in fish farms. A similar situation has already been reported on with respect to the
Gram-negative fish pathogens which were found at high frequency in fish farms in Japan (Aoki et al. 1977). Due to this increased resistance to antibiotics it is likely that streptococcal infections in cultured yellowtail will become more difficult to combat using chemotherapy.

The drug resistance of the non-hemolytic Streptococcus sp. in this study was classified into 2 types: (1) an intermediate-level resistance to MLs, LIM, and TC whose determinants were constitutive and non-transferable; and (2) a high-level resistance to MLs, LIM, and TC or CP whose determinants were inducible and transferable. These 2 types of drug-resistance determinants in Streptococcus sp. were found in various areas of Japan. The difference in the resistance mechanisms of intermediate level resistance and highlevel resistance to MLs and LIM in the genus Streptococcus sp. has become a subject of considerable interest to us. The determinants of middle-level resistance in Streptococcus sp. strains were easily deleted by culturing continuously in a drug-free medium (unpubl. data). This loss in resistance also occurred with strains in which the MLs resistance was induced in vitro (unpubl. data). Studies on the mechanism of middlelevel resistance to MLs, LIM, and TC are currently underway.

The high-level resistance to MLs, LIM, and TC, and to MLs, LIM, and CP was transferred simultaneously to the recipient strains Streptococcus faecalis $\mathrm{JH} 2-2$ and Streptococcus sp. SSS-1, and drug resistance was stable in these recipient cells. Transfer frequencies of drug resistance determinants from resistant strains of Streptococcus sp. to S. faecalis JH2-2 and Streptococcus sp. SSS-1 were nearly the same value, independent 
Table 4. Streptococcus sp. Transfer frequencies of the drug resıstance determinants in various strains. See Fig. 2 for abbreviations Values in parenthesis are no. strains with both drug resistance markers/no. tested strains

\begin{tabular}{|c|c|c|c|c|}
\hline \multirow[t]{2}{*}{ Donor } & \multirow[t]{2}{*}{ Recipient } & \multirow[t]{2}{*}{ Drug } & \multicolumn{2}{|c|}{ Frequencies of transfer } \\
\hline & & & Liquid mating & Filter mating \\
\hline \multirow[t]{2}{*}{ ME8631 } & $\mathrm{JH} 2-2^{\mathrm{a}}$ & $\begin{array}{l}\text { EM } \\
\text { TC }\end{array}$ & $\begin{array}{l}<5.8 \times 10^{-9} \\
<5.8 \times 10^{-9}\end{array}$ & $\begin{array}{l}<6.0 \times 10^{-8} \\
<6.0 \times 10^{-8}\end{array}$ \\
\hline & SSS $-1^{b}$ & $\begin{array}{l}\text { EM } \\
\text { TC }\end{array}$ & $\begin{array}{l}<7.4 \times 10^{-9} \\
<7.4 \times 10^{-9}\end{array}$ & $\begin{array}{l}<1.4 \times 10^{-8} \\
<1.4 \times 10^{-8}\end{array}$ \\
\hline \multirow[t]{2}{*}{ ME87 14} & $\mathrm{JH} 2-2$ & $\begin{array}{l}\text { EM } \\
\text { TC }\end{array}$ & $\begin{array}{l}<1.1 \times 10^{-9} \\
<1.1 \times 10^{-9}\end{array}$ & $\begin{array}{l}<6.0 \times 10^{-8} \\
<6.0 \times 10^{-8}\end{array}$ \\
\hline & SSS-1 & $\begin{array}{l}\text { EM } \\
\text { TC }\end{array}$ & $\begin{array}{l}<8.8 \times 10^{-9} \\
<8.8 \times 10^{-9}\end{array}$ & $\begin{array}{l}<1.0 \times 10^{-8} \\
<1.0 \times 10^{-8}\end{array}$ \\
\hline \multirow[t]{2}{*}{ EH8632 } & JH2-2 & $\begin{array}{l}\text { EM } \\
\text { TC }\end{array}$ & $\begin{array}{l}8.5 \times 10^{-9}(20 / 20) \\
7.4 \times 10^{-9}(20 / 20)\end{array}$ & $\begin{array}{l}3.1 \times 10^{-5}(100 / 100) \\
3.7 \times 10^{-5}(100,100)\end{array}$ \\
\hline & SSS-1 & $\begin{array}{l}\text { EM } \\
\text { TC }\end{array}$ & $\begin{array}{l}1.7 \times 10^{-7}(20 / 20) \\
1.8 \times 10^{-7} \frac{(20 / 20)}{(20)}\end{array}$ & $\begin{array}{l}3.6 \times 10^{-3}(100 / 100) \\
4.8 \times 10^{-3}(100 / 100)\end{array}$ \\
\hline \multirow[t]{2}{*}{$\mathrm{EH} 8702$} & JH2-2 & $\begin{array}{l}\text { EM } \\
\text { TC }\end{array}$ & $\begin{array}{l}4.1 \times 10^{-9}(20 / 20) \\
3.1 \times 10^{-9}(20 / 20)\end{array}$ & $\begin{array}{l}5.8 \times 10^{-4}(100 / 100) \\
7.7 \times 10^{-4}(100 / 100)\end{array}$ \\
\hline & SSS-1 & $\begin{array}{l}\text { EM } \\
T C\end{array}$ & $\begin{array}{l}1.8 \times 10^{-7}(20 / 20) \\
2.6 \times 10^{-7} \frac{(20 / 20)}{(20)}\end{array}$ & $\begin{array}{l}3.9 \times 10^{-3}(100 / 100) \\
5.3 \times 10^{-3}(100 / 100)\end{array}$ \\
\hline \multirow[t]{2}{*}{ KG8703 } & $\mathrm{JH} 2-2$ & $\begin{array}{l}\text { EM } \\
C P\end{array}$ & $\begin{array}{l}9.8 \times 10^{-8}(30 / 30) \\
3.3 \times 10^{-7}(100 / 100)\end{array}$ & $\begin{array}{l}4.1 \times 10^{-4}(100 / 100) \\
3.5 \times 10^{-4}(100 / 100)\end{array}$ \\
\hline & SSS-1 & $\begin{array}{l}\text { EM } \\
C P\end{array}$ & $\begin{array}{l}4.7 \times 10^{-7}(50 / 50) \\
3.4 \times 10^{-6}(100 / 100)\end{array}$ & $\begin{array}{l}4.1 \times 10^{-3}(100 / 100) \\
4.0 \times 10^{-3}(100 / 100)\end{array}$ \\
\hline
\end{tabular}

of the antibiotics selected for each donor strain. The drug-resistant determinants might be located on the $\mathrm{R}$ plasmid or on a transposon. A transferable R-plasmid in streptococci was first detected in a human pathogenic strain of S. faecalis in 1974 (Jacob \& Hobbs 1974). S. faecalis strain JH1 harbored 2 transferable plasmids, pJH1 and pJH2, which encoded for multiple drug resistance and for hemolysin-bacteriosin, respectively (Jacob et al. 1975).

On the other hand, the conjugative transfer of antibiotic resistance determinants can occur in the absence of plasmid DNA when the resistance genes are associated with conjugative transposons (Clewell 1981, Franke \& Clewell 1981). The conjugative transposons transfer in filter mating between a wide range of streptococcal species and other Gram-positive bacteria (Nida \& Cleary 1983, Kathariou et al. 1987, Weiser \& Rubens 1987).

Further work is needed to determine the transfer mechanism of drug resistant determinants in these fish pathogens and to relate it to the mechanisms described for Streptococcus species causing human diseases.

Acknowledgements. We thank Dr T. Miyazaki of Mie University, and the staff of the Prefectural Experimental Fisheries Stations for kindly supplying the strains of non-hemolytic
Streptococcus sp. We also thank Dr D. B. Clewell (University of Michigan, Michigan, USA) for providing the S. faecalis $\mathrm{JH} 2-2$ strains

\section{LITERATURE CITED}

Aoki, T., Kitao, T., Arai, T (1977). R plasmids in fish pathogens. In: Mitsuhashi, S., Rosival, L. Krčméry, $V$ (eds.) Plasmids: medical and theoretical aspect. Avicenum Czechoslovak Medical Press, Prague, p. 39-45

Aoki, T. Takeshita, S., Kitao, T (1983). Antibacterial action of chemotherapeutics agents against non-hemolytic Streptococcus sp. isolated from cultured marine fish, yellowtail Seriola quinqueradiata. Bull. Jap. Soc. Sci. Fish. 49: $1673-1677$

Burdett, V (1980). Identification of tetracycline-resistant Rplasmids in Streptococcus agalactiae (group B). Antimicrob. Ag. Chemother 18: 753-760

Clewell, D. B. (1981). Plasmids, drug resistance, and gene transfer in the genus Streptococcus. Microbiol. Rev. 45: 409-436

Dunny, G. M., Clewell, D. B. (1975). Transmissible toxin (hemolysin) plasmid in Streptococcus faecalis and its mobilization of a noninfectious drug resistance plasmid. J. Bact. 124: 784-790

Franke, A. E., Clewell, D. B. (1981). Evidence for a chromosome-borne resistance transposon (Tn916) in Streptococcus faecalis that is capable of conjugal transfer in the absence of a conjugative plasmid. J. Bact. 145: 494-502

Horodoniceanu, T., Bougueleret, L., El-Solh, N., Bouanchaud, D. H., Chabbert, Y A. (1979). Conjugative R-plasmids in Streptococcus agalactiae (Group B). Plasmid 2: 197-206 
Hyder, S. L., Streitfeld, M. (1973). Inducible and constitutive resistance to macrolide antibiotics and lincomycin in clinically isolated strains of Streptococcus pyogenes. Antimicrob. Ag. Chemother. 4: 327-331

Jacob, A., Douglas, G. I., Hobbs, S. J. (1975). Self-transferable plasmids determining the hemolysin and bacteriosin of Streptococcus faecalis var zymogenes. J. Bact. 121. 863-872

Jacob, A. E., Hobbs, S. J. (1974). Conjugal transfer of plasmidborne multiple antibiotics resistance in Streptococcus faecalis var zymozenes. J. Bact. 117: 360-372

Japan Society of Chemotherapy (1981). Chemotherapy 29 76-78 (in Japanese)

Kathariou, S., Metz, P., Hof, H., Goebel, W. (1987). Tn916induced mutations in the hemolysin determinant affecting virulence of Listeria monocytogenes. J. Bact. 169: 1291-1297

Kitao, T (1982). The methods for detection of Streptococcus sp. causative bacteria of streptococcal disease of cultured yellowtail (Senola quinqueradiata) - especially, their cultured, biochemical and serological properties. Fish Pathol. 17: 17-26 (in Japanese)

Kusuda, R., Kawai, K. Toyoshima, T., Komatsu, I. (1976). A new pathogenic bacterium belonging to the genus Streptococcus, isolated from a epizootic of cultured yellowtail. Bull. Jap. Soc. Sci. Fish. 42: 1345-1352 (in Japanese)

Responsible Subject Editor Dr T Evelyn, Nanaimo, B.C.. Canada
Lai, C.-J., Dahlberg. J. E., Weisblum, B. (1973). Structure of an inducibly methylatable nucleotide sequence in $32 \mathrm{~S}$ ribosomal ribonucleic acid from erythromycin-resistant Staphylococcus aureus. Biochemistry, N. Y 12: 457-463

Lai, C.-J., Weisblum, B. (1971). Altered methylation of ribosomal RNA in an erythromycin-resistant strain of Staphylococcus aureus. Proc. natn Acad. Sci. USA 68: 856-860

Nida, K., Cleary, P. (1983). Insertional inactivation of streptolysin $S$ expression in Streptococcus pyogenes. J. Bact. 155: 1156-1161

Saito, T., Hashimoto, H., Mitsuhashi, S. (1969). Drug resistance of staphylococci. Decrease in formation of erythromycin-ribosomes complex in erythromycin resistant bacteria. Jap. J. Microbiol. 13: 119-121

Skinner, R., Cundliffe, E., Schmidt, F. J. (1983). Site of action of ribosomal RNA methylase responsible for resistance to erythromycin and other antibiotics. J. biol. Chem. 258: $12702-12706$

Weisblum, B., Siddhikol, C., Lai, C.-J., Demohn, V (1971). Erythromycin-inducible resistance in Staphylococcus aureus: requirements for induction. J. Bact. 106. 835-847

Weiser, J. N., Rubens, C. E. (1987). Transposon mutagenesis of group B streptococcus beta-hemolysin biosynthesis. Infection Immunity 55: 2314-2316

Manuscript first received: October 27, 1988

Revised version accepted: May 15, 1990 